\title{
GENETIC COUNSELLING IN PSYCHIATRY: SCOPE AND CHALLENGES
}

Prosenjit Ghosh ${ }^{1}$

\section{HOW TO CITE THIS ARTICLE:}

Prosenjit Ghosh. "Genetic Counseling in Psychiatry: Scope and Challenges". Journal of Evolution of Medical and Dental Sciences 2014; Vol. 3, Issue 51, October 09; Page: 12008-12018, DOI: 10.14260/jemds/2014/3584

ABSTRACT: A large number of psychiatric disorders have genetic etiology. Effective genetic counseling of high risk population may reduce psychiatric morbidity and mortality. Brain being a highly complex organ, understanding the complex circuits, neurotransmitters and signal transmission is very important in the pathogenesis of psychiatric disorders. Even the genetic causation of most of the psychiatric disorders is not simple and mainly it is polygenic. To be effective the genetic counselor must understand the basic nature of psychiatric illness and the psychiatrist must update himself in the recent advances in molecular genetics. Ethical and cross-cultural issues are also important in genetic counseling.

KEYWORDS: Genetic, Psychiatric disorders, Counseling.

INTRODUCTION: Significant number of couples worldwide are at risk of giving birth to an offspring with severe genetic disorder. However in countries like India, where malnutrition and infections are still a major health problem, genetic counseling is an unaffordable luxury.

An important event in the field of medical genetics was the initiation of Human Genome Project (HGP) ${ }^{1}$ in the mid 1980's. The HGP announced the completion of human DNA (deoxyribonuclieic acid) sequencing in April 2003 and, thereby, enriching the information within the context of the genetic counseling process (Hadley, 2005). ${ }^{2}$ The credit to introduce the term 'genetic counseling' goes to Sheldon Reed in 1947.

He proposed that in order to be effective, genetic counselor must have the knowledge and ability to provide genetic information with respect for the sensitivities, attitudes and reactions of clients (Reed, 1955). ${ }^{3}$ Genetic counseling has also been defined as, "a communication process which, deals with the human problems associated with the occurrence, of a genetic disorder in a family" (Fraser, 1974).. Recently, it has been defined as, "a dynamic psycho-educational process centered on genetic information" (Biesecker \& Peters, 2001). ${ }^{5}$ Most definitions of genetic counseling have emphasized three functions:

- Education (i.e., providing information to individuals and families about genetic contributions to disorders).

- Risk estimation (i.e., providing information about the risk of recurrence of the disorder in relatives of attested individuals).

- Non-directive counselling to facilitate decision making. (Fraser, 1974; Tsuang, 1978; Faraone et al., 1999). $6 \& 7$

BACKGROUND: The brain is the most complex object of investigation in the history of biological science. Its development depends on complex, often non-linear, gene-gene and gene-environment interactions. Each neuron in the brain makes thousands of connections or synapses with neighboring and distant neurons; there are probably more than 100 trillion such connections, and across them each neuron may utilize several of more than 100 chemical neurotransmitters. 
Signals encoded by each neurotransmitter are decoded by the receiving cell, using one or several of the many receptor subtypes that exist for each neurotransmitter. For example, the neurotransmitter serotonin has at least 14 different known subtypes of receptors. Neuro-transmitter receptors initiate complex signaling cascades within nerve cells. These cascades process information, produce immediate outputs, such as a decision to fire, and, at the same time, initiate long-term, activity-dependent changes in the receiving cells which may eventually lead to synaptic plasticity. Each synapse is embedded in one or more neural circuits that can be recruited or engaged with exquisite specificity.

Genetic factors contribute to almost every human disease by conferring susceptibility or resistance, and, if disease occurs, by influencing severity and progression. Gene discovery should have a transforming influence on clinical practice. However, the genetics of behavioral variation and of mental illness has proved enormously complex. It is well established that the risk of mental illness runs in families. Family, twin and adoption studies have shown that, for schizophrenia, autism, manic depressive illness, major depression, attention deficit hyperactivity disorder, panic disorder and other mental illnesses, the transmission of risk is due to heredity. $8 \& 9$

The goal of molecular genetic studies of mental disorders is to identify and clone genes that contribute to the risk of such disorders, influence their course or promote resilience. However, the risk of mental disorders is genetically complex. ${ }^{10 \& 11}$ Genetic complexity means that a trait such as vulnerability to a mental illness results not from a single genetic defect but from the interaction of multiple genes.

These gene-gene interactions need not be simply additive; the function of one gene maybe dependent on the prior function of one or more other genes, a phenomenon known as epistasis ${ }^{12}$. Moreover, even in combination, genes do not appear to fully determine the occurrence of a mental illness but must interact with non-genetic factors.

Indeed, studies of monozygotic twins, i.e. who have $100 \%$ of their DNA in common, performed in relation to schizophrenia and manic depressive illness, ${ }^{13}$ confirm the requirement for non-genetic factors to convert vulnerability into illness. In no mental illness is there $100 \%$ concordance for the illness within monozygotic twin pairs. Complexity may not end with the need for multiple alleles at multiple loci in the genome or with the need for non-genetic factors: it is possible that there is no single required allele for any mental disorder, i.e. different combinations of alleles may influence vulnerability in different families.

BASIC PRINCIPLES: Important basic terms related to genetic inheritance and counseling are as follow:

Nucleic Acid: It contains the genetic instructions specifying the biological development of all cellular form of life. It exists in two forms:

\section{DNA}

Structure: Double stranded

Pyrimidine bases: cytosine $\&$ thymine

\section{RNA}

Single stranded

Cytosine \& uracil 
Chromosomes: It is a complex of protein and nucleic acid, which accommodate unbroken double helix of DNA. In human being there are 23 pairs of chromosomes (22 pairs of autosomes and one pair of sex chromosome).

Gene: It is the fragment of DNA located along the chromosomes.

Allele: Alternative forms of a gene are referred to as alleles. An allele can be dominant or recessive. Locus: It is an exact location of gene on a chromosome.

Homozygous: When a subject possesses two identical alleles at the same locus for a given trait he or she is said to be homozygous for that trait.

Heterozygous: When the subject possesses two different alleles at the same locus for a given trait he or she is said to be heterozygous for that trait.

Twin: Two have born at the same birth.

Monozygotic: developed from a single egg and they share $100 \%$ of genetic information

Dizygotic: twin pair developed from two eggs and they share $50 \%$ of genetic information.

Genetic sharing among family members: First degree relatives: children, sibling, parents (50\%). Second degree relatives: half sibling, aunts, uncles, niece, nephew, grandparents, grandchildren (25\%). Third degree relatives: first cousins (12.5\%).

Phenotype: An observed trait is referred as a phenotype.

Genotype: Genetic information defining the phenotype is called the genotype.

Mendelian Laws there are two laws of inheritance given by Mendel. They are:

Law of segregation: It states that alleles, or alternative gene forms at a single locus, segregate with equal probability. For example, when two heterozygote individuals say Rr meets, then on an average the genotype of the offspring will be $\mathrm{RR}, \mathrm{Rr}$, and $\mathrm{rr}$ in the ratio of 1:2:1. If the allele $\mathrm{R}$ is dominant, the phenotype ratio of the offspring on an average is ( 3 dominant): 1 recessive). If the allele $R$ is not dominant than the phenotype ratio of the offspring on average is ( 1 dominant): ( 2 inter mediate): $(1$ recessive).

Law of Independent Assortment: It states that alleles at different loci assort independently of each other. For example, when two homozygous individuals with genotypes say RRSS and rrss, meets then all the members of first generation will have genotype of RrSs and there will be 16 possible genotypes in second generation.

Non Mendelian Laws: Mendelian laws are relatively straightforward and many diseases follow these patterns. However, there are conditions, which do not follow Mendelian patterns. These are the conditions where one or more than one gene interact with each other or interact with one or more than one environmental factors. Many of the psychiatric disorders and few chronic medical disorders like coronary heart disease, diabetes follow non mendelian pattern. Important non Mendelian laws are:

Pleiotropism: The term refers to the phenomenon in which a single gene is responsible for a number of distinct and seemingly unrelated phenotypic effects. In clinical medicine often an external feature (part of Pleiotropism) which may be in itself benign and insignificant, may point to the presence of serious internal disease and/or to the fact that the person is a carrier of the mutant gene.

Genetic Heterogeneity: Genetic Heterogeneity means that anyone of several genetic mechanisms like mutation at separate loci (locus heterogeneity) or different mutation at single 
locus (allelic heterogeneity) can lead to the same or similar phenotype. It means the phenotype is not necessary an indication of the genotype.

Penetrance: It refers to the proportion of individuals with a genotype known to cause a disease, who develop the disorder.

Variable expressivity: It refers to the extent to which a genotype is expressed.

Polygenic Disorder: It refers to the condition resulting from many genes acting independently. Thus the overall characteristic is the cumulative effect of independent genes.

Multifactorial Disorder: It results from an interaction of one or more genes with one or more environmental factors. This category represents the most common type of genetic disease in children and adults.

GENETIC TESTS: A genetic test is normally defined as "the analysis of human DNA (Deoxyribonucleic Acid), RNA (Ribonucleic Acid), chromosomes, proteins, or certain metabolites in order to detect heritable disease related genotypes, mutations, phenotypes or karyotypes for current or future clinical purposes" (Holtzman \& Watson, 1999). ${ }^{14}$ The definition denotes that the genetic test can be accomplished by directly examining the DNA or RNA that make up gene (direct testing) looking at markers co-inherited with a disease - related gene (linkage testing), assaying some metabolites (biochemical testing), or detecting the chromosomes (Xie \& Wu Mao-Qing, 2006). ${ }^{15}$ Genetic tests have become very important in people's life since there is an increase in public awareness about genes and diseases. Genetic tests include (Callanan \& LeRoy, 2006).16

Diagnostic Testing: It is used to confirm a clinical diagnosis of a genetic condition or syndrome.

Carrier Testing: Genetic testing is also used to determine the genetic status of an individual who is at risk for carrying a gene mutation or genetic condition for a specific disease.

Prenatal Diagnosis: It is performed during a pregnancy for females who are at risk for a specific condition. Issues to consider in prenatal diagnosis are:

- A careful assessment of the reproductive risks, availability of testing, evaluation of the accuracy, and sensitivity of testing should precede prenatal diagnosis.

- A full discussion about any risk to the procedure as well as the limitations of testing should be followed by informed consent.

Genetic Screening: These are the testing for genetic disorders in specific groups of people independent of a family history or clinical features.

Predictive Genetic Testing: This kind of genetic testing is used in healthy individuals for genetic disorders with late onset. There are two types of predictive genetic testing - Presymptomatic Testing \& Susceptibility Testing.

One important fact about genetic test to remember is that the test result can only indicate a degree of vulnerability to a given disease. Though the tests are improving in precision and validity (Baum et al., 1997) ${ }^{17}$ it will never allow us to be sure of the development and moment of occurrence of the disease (Lerman \& Croyle, 1994).18 
Genetic Counseling: There are various methods of genetic counseling - Medical/Preventive model, Decision making model and Psychotherapeutic model. The main aim of medical model is to prevent genetic disease and the primary aim of decision making model is to encourage client make their own decision. Psychotherapeutic model emphasizes that genetic counseling is not merely decisionmaking.

Counselors who adopt this model believe that for counseling to succeed, affective dimensions like personality, motivation, education, values, culture, coping styles, interpersonal dynamics, financial and social resources must be adequately explored.

\section{Indications for genetic counseling:}

Advanced maternal age $(>35)$ or paternal age $(>50)$.

History of a child with birth defect or genetic disorder.

Consanguinity.

Personal or family history suggestive of genetic disorder.

High risk ethnic group.

Ultrasonography or prenatal testing suggesting genetic disorder.

Process of genetic counseling: The process of genetic counseling consists of following steps are information gathering, risk assessment, information giving, psychological assessment, decision making and follow-up.

Information Gathering: First step in genetic counseling is to evaluate the referral purpose and to have an informed consent of the client and the family to get involved in the process. Second and most crucial step for the success of genetic counseling is to assess client's need and expectations from the counseling sessions. Accurate and detailed family history is very important in genetic counseling. Family history should include three generations in the format of a pedigree using the standard symbols.

Risk Assessment: There are three basic principles of calculating risk for known genetic disorders. However, calculation of risk is complicated by factors like reduced penetrance, variable expressivity, use of linked DNA markers, variable age of onset, direct mutation analysis and multiple alleles.

To make the risk assessment more comprehensible, counselor should keep in mind following points:

He should be careful not to let his own perception of the burden of the disorder or magnitude of the risk affect how the information is conveyed.

To avoid making qualitative statements like "risk is high or low" (Walker, 2002). ${ }^{19}$

It is found that clients appreciate direct education about genetics and risk assessment (McLeod et al., 2002).20

Information Giving: This is one of the most difficult steps of genetic counseling. A study by Leonard et al. (1972) ${ }^{21}$ revealed that only $20 \%$ of clients correctly recollected the counseling information and only half of counseling recipients recalled enough to make an informed choice. Following techniques will enhance the process of information giving: 
Use of diagrams and visual aids can make difficult concepts more comprehensible. It should also be kept in mind that genetic lessons do not overshadow the counseling session. Finally, at the end of the sessions a letter can be given to the client summarizing historical data, test result, diagnosis, information about etiology, prognosis, genetic risk etc. This letter can serve as a review of the whole process to which the client can refer at any time (Walker, 2002). ${ }^{22}$

Psychological Assessment and Counseling: A client's psychological state is very important as it will decide how much information he has processed both cognitively and emotionally. To be effective, counselor must understand the common emotional reactions to genetic information and ability to differentiate normal and appropriate responses from underlying psychopathology (Walker, 2002). ${ }^{22}$

A client's capacity to understand complex information should be assessed. Any misconception regarding genetic diseases should be clarified. It is important to detect presence of depression, suicidal ideation etc (Lerman \& Croyle, 1994; Shiloh, 1996). ${ }^{23 \& 24}$ Assessment of coping style is also important as this forms the base of success of any intervention (Stiefel et al., 1997). ${ }^{25}$

Decision Making: Taking decision in genetic disease is difficult as all the information is based on uncertain and probabilistic data (Freedman, 1998; Welch \& Burke, 1998). ${ }^{26 \& 27}$ It is found that many clients want information but do not prefer to assume responsibility for a medical disorder (Benbassant et al., 1998). ${ }^{28}$ The counselor may help the client to think about different alternative by imagining how each alternative would affect his/her and family members' life.

Follow-Up: It is an important component of genetic counseling. It helps in evaluating client's understanding of the information, allows an opportunity for further questions to be addressed and provides further support to the client (Hadley, 2005; Walker, 2002).2 \&22

Non-directive counseling can be defined as providing information in a manner that does not promote or encourage one particular course of action over another and is best used in the contest of reproductive decisions (Hadley, 2005) ${ }^{2}$. Non-directive genetic counseling respects client's autonomy and also acts as a safeguard for counselor against legal complications.

GENETIC COUNCELLING IN PSYCHIATRY: Many of the psychiatric disorders seem to have genetic contributions. Related to the limitations of available information about genetic risks and the inability to individualize risks due to the absence of genetic testing, genetic counseling for psychiatric disorder has received little attention from the professionals.

Role of Genetic Counseling in Psychiatry: Psychiatric patients and their relatives may request genetic counseling for a variety of reasons:

1. Questions about recurrence risks of psychiatric disorders,

2. Questions regarding the genetic basis of psychiatric disorders and the availability of genetic testing (Tsuang, 1978) ${ }^{6}$.The genetic counseling may alter misperceptions, dispel inaccurate beliefs, and provide adequate information about course, prognosis, risk factors, and available treatment options. 
Recurrence risk for major Psychiatric Disorders: The discussion of recurrence risk for psychiatric disorders can be challenging; Reasons are; (Finn and Smoller, 2006). ${ }^{29}$

In psychiatry recurrence risk estimates are based on empiric risks. It is important to note that these risks are based on particular ascertained study populations and are not specific to the clients' family, where the risk could be far higher or lower based on the particular constellation of genetic and environmental factors that may be present.

The discussion can also address the notion that psychiatric illness is likely due to the effect of multiple genes in concert with environmental risk factors, that genes may confer risk for a disorder, but that the expression of the phenotype and the probability of the disorder's occurring may be difficult to predict.

Furthermore, for some psychiatric conditions risks for family members may also exist for related disorders- for example increased risks for all mood disorders among family members of bipolar patents (Smoller \& Finn, 2003). ${ }^{30}$

Individualizing Risks: Empiric risks in individual families may be far higher or lower depending on the mode of transmission. Several factors may help determine whether particular families may be at the higher or lower risk.

First, the presence of a greater number of affected family members represent a more highly genetic form of the disorder and thus a higher risk of disease recurrence.

Second, early onset of disorder may reflect greater genetic loading, and in the case of several disorders, recurrence risks have been shown to be elevated when the age of onset of symptoms in affected individuals is early (Weissman, et al., 1984). ${ }^{31}$

Third, sex of affected and at risk family members may influence recurrence risks, as evidenced by the risk of autism being approximately 3-4 times in males than females (Lord, et al, 1982). ${ }^{32}$

In general, it is important to highlight the limitations of the information, and to discuss how risks are derived, the spectrum of diagnosis assessed in the supporting family studies, and the difference between empiric and individualized risks.

Most of the psychiatric disorders are genetically complex and to result from the interplay of multiple genes and environmental factors. For these disorders the onset of illness may require the additive or interactive effect of multiple genes, with each individual gene contributing a small amount to risk. Addictive or interactive effects of environmental risk factors may also contribute to the risk. In addition to making the search for susceptibility genes very difficult, the small individual effects of these genes means that, even if we can identify the genes, the feasibility and value of genetic testing may be limited (Finn \& Smoller, 2006). ${ }^{29}$

Challenges of genetic counseling for psychiatric Problems: Deficits in knowledge of psychiatric diagnoses, psychiatric genetics, and psychosocial issues involved in counseling were standing as the obstacles for effective counseling.

In one study related to their ability to provide genetic counseling for major psychiatric disorders genetic counselors reported feeling of "somewhat" to "very" unprepared to raise the issue of psychiatric disorder with consultants that is $32 \%$ of practicing genetic counselors and $67 \%$ of genetic counseling students (Peay \& Mclnerney, 2002). ${ }^{33}$ 
Giving genetic counseling for complex disorders is a challenge to professionals and the gap in knowledge might become a limiting factor in the ability of a psychiatrist to give effective counseling (Finn \& Smaller, 2006). ${ }^{29}$

CROSS CULTURAL GENETIC COUNCELLING: The communication in counseling process becomes problematic if the counselor and client come from different languages. The use of interpreter may create issues related to confidentiality, freedom and power. Client's religious beliefs and cultural background also affect the decision-making process and may show strong objections towards certain issues-like prenatal diagnosis and possible termination.

The clinician should be aware of and respectful towards the clients' religious beliefs and cultural traditions. Another important problem is stereotyping. Clinician should be careful to the tendency to make assumption about the likely response of the individual only on the basis of his existences in a particular group (Clarke 2002). ${ }^{34}$

GENETIC LITERACY: Nothing will be able to prevent the misuse of genetic information if those who collect and use it do not understand its significance correctly. So, the best ways to decrease the risks of genetic discrimination are to promote better understanding of human genetics. Several forms of education seem to be needed if we are to become a genetically literate society.

The genetic technologies become more widely available; the demand for health professionals trained to addresses the clinical and ethical challenges of managing and interpreting genetic information will quickly outpace the current supply.

An important target for educational efforts is for those who are in position to influence the public's response to genetic advances: the news media, the scholarly and scientific community, and the public policy makers (Juengst, 2005). ${ }^{35}$

GENITIC COUNSELING IN THE FUTURE: The future of genetic counseling lies in counseling excellence, professional education, further specialization, anticipatory guidance, and research and academic development.

Confidentiality: Providers may feel more of an obligation to notify at-risk family members when a treatment or intervention could reduce morbidity or mortality. As genes are identified that lead to treatable conditions such as diabetes and hypertension, counselors will find it increasingly difficult to honor the client's request not to notify family members.

Future Counseling Expertise: The most important feature of the changing genetic counseling field will emphasize on short-term psychotherapy. When people learn that they are at increased health risk, they face significant emotional adjustment problems. Facilitating the acceptance of test results and addressing client's anxieties about their health will continue to be an important role for genetic counselors. Counselors will need to hear, respect and encourage clients who learn test results in their efforts to notify family members, adjust their lifestyle choices, and pursue certain early detection or prevention activities (Biesecker, 1998). ${ }^{36}$

CONCLUSION: Ethical issues are major importance in medical genetics. Each of the new discoveries coming with new challenges and new dilemmas for which there are no easy answers. 
Genetic counseling is looking for a bright future, through counseling excellence, professional training, specialization, anticipatory guidance and research.

\section{REFERENCES:}

1. Genetic Counseling Resources, Human Genome Project. http://www.ornl.gov/sci/techresources/HumanGenome/medicine/genecounseling.shtml

2. Hadley DW. Genetic counseling. Sadock BJ, Sadock VA, Comprehensive Textbook of Psychiatry 2005 Lippincott Williams \& Wilkins; Philadelphia: USA.

3. Reed S. Counseling in Medical Genetics 1955: Philadelphia: Saunders.

4. Fraser FC. Genetic counseling. American Journal of Human Genetics 1974; 26: 636-61.

5. Biesecker BB, Peters KF. Process and studies in genetic counseling: Peering into the black box. American Journal of Medical Genetics. 2001; 106: 191-198.

6. Tsuang MT. Genetic counseling for psychiatric patients and their families. American Journal of Psychiatry 1978; 135:1465-75.

7. Faraone SV, Tsuang MT, Tsuang DW. Genetics of mental disorders: a guide for students, clinicians, and researchers 1999; Guilford: New York.

8. Craddock N, Jones I. Genetics of bipolar disorder. Journal of Medical Genetics, 1999, 36: 585594.

9. Genetics and mental disorders: report of the National Institute of Mental Health's Genetics Work-Group. Rockville, Maryland; National Institute of Mental Health; 1998 (http://www.nimh.nih.gov/research.htm).

10. Hyman SE. Introduction to the complex genetics of mental disorders. Biological Psychiatry, 1999, 45: 518-521.

11. Barondes SH. An agenda for psychiatric genetics. Archives of General Psychiatry, 1999, 56: 549552.

12. Frankel WN, Schork NL. Who's afraid of epistasis? Nature Genetics, 1996, 14: 371-373.

13. Suddath RL et al. Anatomical abnormalities in the brains of monozygotic twins discordant for schizophrenia. New England Journal of Medicine, 1990, 322: 790.

14. Holtzman NA, Watson MS. Promoting safe and effective genetic tests in the United States: work of the task force on genetic testing. Clinical Chemistry 1999; 45: 732-738.

15. Xie Wu Mao-Qing. A review of genetic testing. Chinese Journal of Biotechnology 2006; 22: 338343.

16. Callanan NP, Le Roy BS. Genetic counselling and the physician-patient relationship. Sharp NF \& Carter RF Eds. Genetic Testing: Care, Consent, and Liability 2006; John Wiley \& Sons, Inc: USA.

17. Baum A, Friedman A.L, Zakowski SG. Stress and genetic testing for disease risk. Health Psychology 1997; 16: 8-19.

18. Lerman C, Croyle R. Psychological issues in genetic testing for breast cancer susceptibility. Archives of Internal Medicine 1994; 154: 609-616.

19. Walkar AP, Genetic counseling. Rimoin DL, Connor JM, Pyerit RE, Korf BR. Eds. Principles and Practice of Medical Genetics 2002: Harcourt Publishers Limited; Churchill Livingstone, USA.

20. MacLeod R, Crauford D, Booth K. Patient's perceptions of what makes genetic counselling effective: An interpretive phenomenological analysis. Journal of Health Psychology 2002; 7: 145-156. 


\section{REVIEW ARTICLE}

21. Leonard CO, Chase GA, Childs B. Genetic counselling: a consumer's view. New England Journal of Medicine 1972; 287: 433-439.

22. Walkar AP, Genetic counselling. Rimoin DL, Connor JM, Pyeritz RE, Korf BR. Eds. Principles and Practice of Medical Genetics 2002: Harcourt Publishers Limited; Churchill Livingstone, USA.

23. Lerman C, Croyle R. Psychological issues in genetic testing for breast cancer susceptibility. Archives of Internal Medicine 1994; 154: 609-616.

24. Shiloh S. Genetic counselling: A developing area of interest for psychologists. Professional Psychology: Research and Practice 1996; 27: 475-486.

25. Stiefel F, Lehmann A, Guex P. Genetic detection: The need for psychosocial support in modern cancer prevention. Supportive Care in Cancer 1997; 5: 461-465.

26. Freedman TG. Genetic susceptibility testing: Ethical and social quandaries. Health and Social Work 1998; 23: 214-222.

27. Welch HG, Burke W. Uncertainities in genetic testing for chronic diseases. Journal of American Medical Association 1998; 280: 1525-1527.

28. Benbassat J, Pilpel D, Tidhar M. Patients' preferences for participation in clinical decision making: A review of published surveys. Behavioral Medicine 1998; 24: 81-88.

29. Finn CT, Smaller JW. Genetic counseling in psychiatry. Harvard Review of Psychiatry 2006; 14: 109-121.

30. Smoller JW, Finn CT. Family twin and adoption studies of bipolar disorders. American Journal of Medical Genetics 2003; 123: 48-58.

31. Weissman MM, Wickramaratne P, Merikangas KP. Onset of major depression in early adulthood. Increased familial loading and specificity. Archives of General Psychiatry 1984; 41:1136-43.

32. Lord C, Schopler E, Revicki D. Sex differences in autism. Journal of Autism Developmental Disorders 1982; 13: 317-30.

33. Peay H, McInerney J. A pilot study on psychiatric genetic counseling: counselor's needs. Journal of Genetic Counseling 2002; 11: 485.

34. Clarke AJ. Ethical and social issues in clinical genetics. Rimoin DL, Connor JM., Pyeritz RE Korf BR. Eds. Principles and Practice of Medical Genetics 2002. Harcourt Publishers Limited; Churchill Livingstone.

35. Juengst ET. The Ethics of prediction: Genetic risk and the physician parent relationship. Eds. Monagle JF, Thomasma DC. Health Care Ethics - Critical Issues for the 21 ${ }^{\text {st }}$ Century. 2005; Jons \& Bartlett Publishers: Massachusets.

36. Biesecker BB. Future directions in genetic counselling: Practical and ethical considerations. Kennedy Institute of Ethics Journal 1998; 82: 145-160. 


\section{REVIEW ARTICLE}

\section{AUTHORS:}

1. Prosenjit Ghosh

\section{PARTICULARS OF CONTRIBUTORS:}

1. Assistant Professor, Department of Psychiatry, Silchar Medical College, Silchar, Assam.

\section{NAME ADDRESS EMAIL ID OF THE} CORRESPONDING AUTHOR:

Dr. Ghosh Prosenjit

Parijat Apartment,

House No. 2BID,

College Road, Ambicapatty,

Silchar-788004, Assam.

Email: p_ghosh72@yahoo.com

Date of Submission: 16/09/2014. Date of Peer Review: 17/09/2014. Date of Acceptance: 30/09/2014. Date of Publishing: 08/10/2014. 